comfortable if the hole points downwards. The distance from the exterior to the nasopharynx is about three inches. The catheter can be conveniently fixed to the cheek by a piece of sticking-plaster. Prolonged personal use shows that passing the gas through warmed water lessens the discomfort; it also has the advantage of making the flow of gas visible. A flow meter is convenient, but not essential. The flow should be as fast as the patient will readily tolerate. A reducing valve or some sort of fine adjustment is most desirable, but in any case the catheter should be disconnected during any manipulation of the taps. Care should be taken to keep the tube leading to the patient free from water.

\section{A New Modification.}

As might be expected from the superiority of the facemask over the catheter in raising the alveolar oxygen, it has also been observed clinically that the former method may remove entirely a cyanosis which the latter had only been able to lessen. Consideration of this, and of the drawbacks of the face-mask mentioned above, has led to the trial of a mouth-mask which allows the patient to breathe oxygen by the mouth while leaving the nose free to breathe air. It appears to be more comfortable and more willingly borne by the patient. The front is covered by a large flap of thin rubber, which gives a minimal resistance to expiration. The tube connecting the oxygen - bag comes in underneath. The mouthpiece is provided with an inflated rubber cushion to make it fit comfortably; it is held in place by a piece of elastic which passes behind the head. Oxygen is breathed from a bag in which the gas collects during expiration, as described by Haldané. Gilchrist and Davies ${ }^{8}$ have described a modification of this principle, which is simple to make and highly efficient in use.* Chart 2 shows the effect on the alveolar oxygen; the highest figures are obtained if the nostrils are lightly plugged with cotton-wool. By this means in another subject the average alveolar oxygen was $650 \mathrm{~mm}$.; but it is not considered advisable to maintain such high pressures indefinitely, since there is experimental evidence that pure oxygen for three days causes pulmonary oedema in certain animals. ${ }^{12}{ }^{13}$ Further work is in progress on the clinical use of this apparatus and the effect it has on the oxygen in the arterial blood.

BIBLIOGRAPHY.
1 Barcroft : Anoxaemia, Lancet, 1920, ii, 487.

Haldane, J. S.: Recent Developments in the Therapeutic Use of Oxygen. Contributed to Medical and Biological Fesearch, dedicated to Usier, 1919, I, 550.

3 Barach and Woodwell: Arch. Int. Med., 1921, xxviii, 394, p. 421.

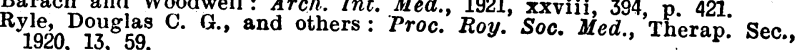
$1920,13,59$

5 Meltzer: Journ. Amer. Med. A8soc., 1917, 1xix, 1150.

Barcroft, Hunt, and Dufton: Oxygen Chamber, Quart. Journ. Med., 1920, xiii, 179

Proc. : Oxygen Bed Tent, Journ. Physiol., 50, May 24th, 1921,

Proc., p. 20.

10 Roth : Journ. Lab. and Clin. Med., 12, January, 1927, p. 388

Davies, H. W., and Rabinovitch : Proc. Physiol. Soc., December, 1927, 11 Bourne: Lancet, 1922 , ii, 23.

12 Smith, Lorrain : Journ. Physiol. 1899, 24, 19.

13 Binger, Faulkner, and Moore: Journ. Exper. Med., 45, 1927, p. 849.

\section{INTUSSUSCEPTION IN AN ADULT DUE TO A POLYP OF MECKEL'S DIVERTICULUM.}

\section{IAN MACDONALD, M.D., HUELVA, SPAIN.}

A CRITICal study ${ }^{1}$ of intussusception in the adult shows that in 36 per cent. of the cases an intestinal tumour is the predisposing cause. The tumours in order of frequency are: simple polyps, lipomata, fibromyomata, and adenomata; malignant growths rarely occur in this type of intestinal obstruction. In the following case the intussusception was caused by a pediculated polyp which arose from a Meckel's diverticulum.

A man, aged 40, who had previously enjoyed excellent health, complained of slight discomfort round the navel and in the right iliac fossa. He, however, contínued to eat; work, and live his ordinary daily life, and his kowels at this time acted normally. Both this and the mouth-mask are obtainable from Siebe Gorman,
Westminster Bridge Road.
Four days later, after his evening meal, he was attacked by severe abdominal pain, accompanied by vomiting, which had continued, in spite of all treatment, for ten days, when he was admitted to hospital. The vomited matter had been first food, then bile, and latterly it had developed a faecal odour. During these ten days the bowels, in spite of purges and enemata, were these ten days the bowels, in spite of purges and enemata, were
absolutely constipated. On admission the vomiting had ceased for twelve hours, but the pain continued, the pulse was 80 , and the abdomen was distended, but not tense. Peristaltic waves were clearly visible, running transversely in the "ladder pattern." The hernial sites and the rectum were negative and no tumour could be felt in the abdomen.

About six hours after admission the abdomen was opened mesially below the navel, under morphine, intravenous somnifene, and intermittent ether anaesthesia. Coils of very dilated small bowel bulged into the wound, while the caecum was brought out with a little difficulty. To its inner side twisted coils of small with a little difficulty. To its inner side
intestine could only be partly unravelled, and further examination revealed a hard mass in the interior of the caecum. It now became obvious that an ileo-caecal intussusception had occurred, so the intracaecal mass was gently pushed out through the. ileo-caecal valve and the intussusception rapidly: reduced. On continuing to push the tumour further continuing to push the tumour further
along towards more healthy bowel it was suddenly arrested about two feet from the caecum, its pedicle of at tachment arising from the inner aspect of a broadish Meckel's diverticulum about the size of the tast joint of - the thrub. The diverticulum was of a blackishpurple hue; the proximal ileum was intensely congested and much distended, whîle the distal portion was narrowed.

while the distal portion was narrowed.

Resection of the parts was decided on,
so the bowel was divided fully six inches so the bowel was divided fully six inches
proximal, and ahout three inches distal, to the pedicle of the tumour: After careful haemostasis of the sodden mesentery the intestinal ends were rapidly closed by a pursestring suture over a Parker-Moynihan clamp, and lateral anastomosis was performed. Finally an enterostomy was performed about eight inches proximal to the anastomosis on the dilated loop; a small tube being rapidly fixed in the bowel by a couple of pursea small tube being rapidy fixed was then fixed by a single catgut string sutures. The intestine was then fixed by a single catgut stitch to the peritoneum of the wound; the abdomen was closed tranquilly all night; the pulse never exceeded 100 , and there was no vomiting. The ileostomy tube drained very freely for fortyno vomiting. and the bowels moved naturally on the third day; the tube became loose on the fifth day, and the patient left the clinic a month after his operation, with the. wound soundly healed.

In this case, since the intussusception was reducible, the question arises whether excision of the diverticulum, extraction of the polyp, and transverse suture of the bowel might not have sufficed. A table of statistics, however, in Gueulette's thesis ${ }^{2}$ shows that in 104 cases resection was performed 60 times with 41 recoveries. In intestinal obstruction after the obstaclo is removed experience leads to the belief that enterostomy on the distended proximal loop is an important factor in the successful issue.

The specimen, placed by Professor D. P. D. Wilkie in the museum of the surgical department, Edinburgh University, is a thick polyp about three inches long, springing from the inner surface of a flattish Meckel's diverticulum. Histological examination showed that the intestinal polyp consisted of fibrous tissue into which haemorrhage had taken place. There was no evidence of malignancy.

REPERENCES.

1 Brocq and Gueulette : Journ. 

\section{BLASTOMYCOSIS OF EYE AND FACE SECONDARY TO LUNG INFECTION. \\ BY}

ARNOLD S. FERGUSON, F.R.C.S.ED., AURAL AND OPHTHALMIC SURGEON, JERSEY GENERAL HOSPITAL.

Fungus involvement of the lungs, according to the statistics of Colonel Marett, medical officer of health and States bacteriologist, is of frequent occurrence in Jersey. The following case is of great interest, as the eye and face conditions are definitely secondary to the lung infection.

A man, aged 58, was sent to me by Dr. Sydney Whitaker. The patient was very evidently ill and emaciated. There was slight sclero-keratitis with accompanying ciliary injection of the left eye. Within a week the limbal conjunctiva and episcleral tissue showed 